\title{
Acceptance and commitment therapy for clients institutionalized for severe substance-use disorder: a pilot study
}

This article was published in the following Dove Press journal:

Substance Abuse and Rehabilitation

26 July 2017

Number of times this article has been viewed

\author{
Gabriella Svanberg' \\ Ingrid Munck ${ }^{2}$ \\ Maria Levander ${ }^{3}$ \\ 'Department of Substance Abuse, \\ The Swedish National Board of \\ Institutional Care, Stockholm, \\ ${ }^{2}$ Department of Education and Special \\ Education, University of Gothenburg, \\ Gothenburg, ${ }^{3}$ Department of Clinical \\ Neuroscience, Karolinska Institute, \\ Stockholm, Sweden
}

Background: Individuals with substance-use disorder (SUD) often have co-occurring mental health disorders and decreased executive function, both of which are barriers to sustained rehabilitation. Clients with severe SUD can be institutionalized in The Swedish National Board of Institutional Care but are difficult to engage and dropout rates remain high. Recent studies suggest that acceptance and commitment therapy (ACT) is an effective treatment for mental health and SUD.

Objectives: The overall aims of the present pilot study were to explore a manual-based ACT intervention for clients institutionalized for severe SUD and to describe the effects on mental health, psychological flexibility, and executive function. This pilot study is the first to use a manual-based ACT intervention within an inpatient context.

Methods: Eighteen participants received a seven-session ACT intervention tailored for SUD. Statistical analyses were performed for the complete data $(n=18)$ and on an individual level of follow-up data for each participant. In order to follow and describe changes, the strategy was to assess the change in 13 clinical scales from pre-intervention to post-intervention.

Results: Results suggested that there was no change in mental health and a trend implying positive changes for psychological flexibility and for 9 of 10 executive functions (e.g., inhibitory control, task monitoring, and emotional control).

Conclusion: The pilot study suggests clinical gains in psychological flexibility and executive functions both at the Institution regulated by the Care of Alcoholics and Drugabuser Act (also known as LVM home) and at the individual level. Since the sample size does not provide adequate statistical power to generalize and to draw firm conclusions concerning intervention effects, findings are descriptive and preliminary in nature. Further development and implementation of ACT on a larger scale study, including the maintenance phase and a follow-up, is needed.

Keywords: acceptance and commitment therapy, substance-use disorder, psychological flexibility, executive function

\section{Introduction}

Substance-use disorder (SUD) is a major health problem and is often associated with substantial social and personal costs. ${ }^{1,2}$ According to the Diagnostic and Statistical Manual of Mental Disorders, Fifth Edition (DSM-5), ${ }^{3}$ a diagnosis of SUD (mild, moderate, or severe alcohol or drug use) is based on the evidence of impaired control, social impairment, risky use, and pharmacological criteria. Treatments are available, but individuals are difficult to reach and dropout rates remain high. To address issues related to the mismatching of treatment to client needs, there is a need for new therapies that are well tailored, effective, and evidence based.

Every year, thousands of adults diagnosed with SUD are institutionalized by The Swedish National Board of Institutional Care (SiS), a government agency that provides 
individualized compulsory care. Clients forced by law into these institutions - Institutions regulated by the Care of Alcoholics and Drugabuser Act (LVM homes) - are diagnosed with SUD, and many also suffer from other mental health disorders, ${ }^{4}$ such as sleeping disorders, ${ }^{5}$ depression, ${ }^{1}$ anxiety, ${ }^{6}$ and stress, ${ }^{5}$ all of which need to be managed properly since they often trigger relapse. ${ }^{7,8}$ Clients at LVM homes constitute an especially high-risk group since they not only suffer from mental health disorders but often also from brain trauma and attention-deficit/hyperactivity disorder (ADHD). ${ }^{9}$ These conditions can negatively impact the prefrontal cortex and thus increase the risk for executive dysfunction, such as decreased inhibition, ${ }^{10}$ which in turn increases the risk of relapse in SUD. ${ }^{11}$ Hence, in addition to behavior challenges relating to rehabilitation, practitioners must take the emotional and cognitive functioning of individuals with SUD into consideration.

Several randomized controlled studies have shown that relatively short acceptance and commitment therapy (ACT) interventions have positive effects on mental health disorders $^{12,13}$ and on SUD. ${ }^{7,14-19}$

The general objective in ACT is to instill psychological flexibility "allowing individuals to contact, take in, and evaluate their current circumstance, so as to act in line with one's values without giving in to impulses" ${ }^{13,20}$ Emphasizing acceptance of inner discomfort by shaping a new, open, aware and flexible way of relating to internal experiences ${ }^{21-23}$ involves a set of interrelated mental functions named executive functions. ${ }^{24,25}$ Executive functions can be divided into behavior regulation (inhibiting, shifting of attention, emotional control, and self-monitoring) and metacognition (initiating, working memory, planning/organizing, task monitoring, and organizing of materials), ${ }^{10}$ critical for individuals with SUD to follow through with treatment plans. ${ }^{26-29}$ Recent studies show that executive functions can be trained..$^{30,31}$

\section{Aim of the pilot study}

The aims of the present pilot study were to explore and describe the effects of a 3-week, tailor-made, client-centered ACT intervention on mental health, psychological flexibility, and executive function of participants institutionalized for severe SUD.

\section{Methods}

\section{ACT intervention}

The present ACT manual used in this study was developed by the first author in 2015 and was based on the six key processes in ACT (present moment, defusion, acceptance, self as context, values, and committed action). ${ }^{32,33}$ The manual included seven $\times 90$-minute sessions spread out evenly during a 3 -week period and was focused on training in how to use the ACT prin- ciples. The intervention included daily mindfulness practices, 10 minutes each, using audio-guided instructions. Self-practice included evidence-based mindfulness practices developed by Schenstrom (further researched in Sundquist et al). ${ }^{34}$

\section{ACT instructors and coaches}

Psychologists and social counselors, two from each of three different LVM homes, participated in a 4-day ACT program presented by a senior psychologist Livheim, trained in ACT, spread out evenly over an 8-week period to become ACT instructors. In parallel with the ACT program, they trained the rest of the personnel at the LVM homes in basic knowledge about ACT and on how to coach the participants.

\section{Participants}

Out of a total of 26 individuals who were recruited by the instructors, 18 participants fulfilled all enrollment data requirements. Inclusion criteria for the study were as follows: 1) ages 21-65 years, 2) diagnosed with a severe SUD according to ICD-10 and DSM-5 (no distinction was made between alcohol and drug use), and 3 ) institutionalized at an LVM home. Exclusion criteria were severe psychiatric symptoms, such as dementia or psychosis, which could interfere with the intervention. Four participants were excluded due to incomplete data: one was moved from the institution; one was diagnosed with Asperger's syndrome and ADHD and excluded due to difficulties being in a group situation, one was incarcerated; and one escaped from the institution (Table 1).

\section{Ethics statement}

The study was approved by the Regional Ethics Review Board of Stockholm, Sweden. Written informed consent was obtained from all participants before the study started.

\section{Measures}

\section{Mental health status}

To measure change in mental health scores between preintervention and post-intervention, the Depression, Anxiety and Stress Scale - 21 (DASS-21), ${ }^{35}$ a 21-item self-report measure designed to assess mental health, was used. Responses were reported on a 4-point Likert scale, ranging from 0 (did not apply to me at all) to 3 (applied to me very much or most of the time). High scores on the DASS-21 indicated a high level of depression, anxiety, or stress.

\section{Psychological inflexibility}

To measure change in psychological flexibility between pre-intervention and post-intervention, the Acceptance and Action Questionnaire - II (AAQ-II) was used, which is a 
Table I Demographic and diagnostic information for institutionalized participants with SUD $(n=18)$

\begin{tabular}{|c|c|c|c|c|c|c|}
\hline LVM home/participant ID & Age (years) & Gender & Depression & Anxiety & Stress & Diagnosis \\
\hline \multicolumn{7}{|l|}{ LVM home/A } \\
\hline AID02 & 49 & $\mathrm{~F}$ & - & -- & - & Not diagnosed \\
\hline AID03 & 49 & $\mathrm{~F}$ & ++ & ++ & + & Not diagnosed \\
\hline AID06 & 42 & $\mathrm{~F}$ & ++ & ++ & ++ & PTSD \\
\hline AID07 & 29 & $\mathrm{~F}$ & ++ & - & + & PTSD \\
\hline \multicolumn{7}{|l|}{ LVM home/B } \\
\hline BID0I & 27 & M & - & - & +- & ADHD \\
\hline BID02 & 57 & M & ++ & ++ & ++ & PTSD \\
\hline $\mathrm{BID03}$ & 59 & M & ++ & ++ & ++ & Bipolar disorder \\
\hline BID05 & 57 & M & +- & ++ & ++ & Not diagnosed \\
\hline BID07 & 42 & M & +- & + & + & Not diagnosed \\
\hline \multicolumn{7}{|l|}{ LVM home/C } \\
\hline CIDOI & 43 & M & + & +- & +- & ADHD \\
\hline CID02 & 50 & M & ++ & + & ++ & Social phobia \\
\hline $\mathrm{CID03}$ & 32 & M & + & + & + & Conductive disorder \\
\hline CID05 & 42 & M & -- & -- & -- & ADHD, OCD, borderline \\
\hline CID06 & 49 & M & +- & ++ & - & ADHD \\
\hline CID07 & 33 & M & - & -- & +- & Not diagnosed \\
\hline CID08 & 39 & M & + & ++ & - & ADHD, borderline \\
\hline CID09 & 60 & M & ++ & +- & ++ & Not diagnosed \\
\hline CIDIO & 24 & $M$ & - & -- & - & ADD \\
\hline
\end{tabular}

Note: See Table 2 for coding key of DASS-2I ranging from ++ high high positive to -- low low negative.

Abbreviations: LVM home, Institution regulated by the Care of Alcoholics and Drug Abuser Act; SUD, substance-use disorder; F, female; PTSD, post-traumatic stress syndrome; M, male; ADHD, attention-deficit/hyperactivity disorder; OCD, obsessive compulsive disorder; ADD, attention-deficit disorder; DASS-2I, Depression, Anxiety and Stress Scale - 21

modified version of the original AAQ, ${ }^{36}$ which assesses experiential avoidance. It is currently the standard method of measuring psychological flexibility and measures nine aspects of executive function, utilizing 75 items across nine subscales.

\section{Executive dysfunction}

The Behavior Rating Inventory of Executive Function - Adult Version (BRIEF-A) ${ }^{10}$ is a self-assessment form measuring nine aspects of executive function, utilizing 75 items across nine subscales. The total score, the global executive composite (GEC), reflects overall functioning. The two summary index scales are the Behavioral Regulation Index (BRI), composed of four subscales (inhibition, shift, emotional control, and self-monitoring), and the Metacognition Index (MI), composed of five subscales (initiation, working memory, planning/organizing, task monitoring, and organization of materials). Each of the nine subscales is measured on a standardized $T$-scale according to the manual, for which a high score indicates high dysfunction. $T$-scores $\geq 65$ are considered as clinically significant. The response format for items on the BRIEF-A is never, sometimes, and often.

\section{Data collection}

Data were collected pre intervention (1 day before the ACT intervention), after each session, and post-intervention
(1 day after the ACT intervention). The DASS-21, AAQ-II, and BRIEF-A were administered pre-intervention and postintervention. The AAQ-II was completed after each session during the entire intervention phase. Participants received gift cards with a value of $\$ 50$.

\section{Statistical analyses}

Statistical analyses were performed on the complete data $(n=18)$ and on an individual level. Changes were assessed and described in the 13 clinical scales from pre-intervention to post-intervention. The individual results are the scores for the clinical scales assessing mental health (depression, anxiety, and stress), psychological flexibility, and executive function (i.e., four subscales of BRI and five subscales of MI). $T$-scores were available for the in-depth summary analysis of the executive functions, defined in the BRIEF-A manual. ${ }^{10}$ In order to compare individuals on all the clinical scales, each subscale was recoded into a common 5-point categorical variable ranging from low low negative- to high high positive-labeled assessment categories defined in Table 2.

The cutoff points between categories were guided by available manuals, whereby the threshold for the high high positive $(++)$ category corresponded to the normal/healthy category and the low low negative (-) category to the most severe problem category. 
Table 2 Coding clinical scales and items into common assessment categories

\begin{tabular}{lllll}
\hline Variable/original clinical scale or item & \multicolumn{4}{l}{ Coding scheme for scores into assessment categories } \\
\cline { 2 - 5 } & $\begin{array}{l}\text { High high } \\
\text { positive }\end{array}$ & Ligh & Medium Low low negative \\
& & & & \\
\end{tabular}

Abbreviations: DASS-2I, Depression, Anxiety and Stress Scale - 2I; AAQ-II, Acceptance and Action Questionnaire - II; BRIEF-A, Behavior Rating Inventory of Executive Function - Adult Version.

The classification key - negative/status quo/positive trend - was developed to report substantial improvements rather than minor changes (see Notes in Table 3).

\section{Results}

\section{Mental health}

There was a balanced frequency distribution between negative change and positive change at an individual level. The majority of the participants reported no change in mental health (Table 3).

\section{Psychological flexibility}

Psychological flexibility from 18 participants was assessed after every session, i.e., seven time points, and the results suggested a trend implying increased psychological flexibility across time and LVM home (Figure 1).

At an individual level, Table 3 suggests a trend implying improved psychological flexibility for twelve clients (67\%) and that four clients maintained status quo and two moved in a negative direction.

\section{Executive function}

The mean $T$-scores (Figure 2) for all BRI subscales (inhibition, shift, emotional control, and self-monitor) appeared to be lower post-intervention, suggesting an increase in behavioral regulation. The subscale inhibition suggested the most positive change followed by self-monitor. $T$-score means on all MI subscales (initiate, working memory, plan/organize, task monitoring, and organization of materials), with the exception of organization of materials, appeared to decrease from pre-intervention to post-intervention. Within the MI subscales, the most positive outcome - according to $T$-score measures - was reported for plan/organize. Results for each of the nine subscales were measured on a standardized $T$-scale, for which a high score indicated high dysfunction.
At an individual level, according to BRIEF-A scores, the most positive changes occurred in the subscale inhibition. As indicated, 8 participants reported a positive tendency, 10 participants maintained the status quo, and no participants showed a negative change (Table 3). Changes appeared to be positive for the emotional control subscale, i.e., six participants reported positive change, 10 maintained status quo, and two reported a negative change.

As reported in Table 3, the change between preintervention and post-intervention across all MI subscales was observed for task monitoring, where seven participants reported a positive tendency, eight participants maintained status quo, and three participants reported a negative change. For initiation, 5 participants reported a positive change, 12 showed no change, and 1 participant reported a negative change. It should be noted that $T$-score means are more affected by outliers than results based on assessment categories, making results from Table 3 more reliable.

\section{Correlations between psychological flexibility and executive function}

Correlations between pre-intervention for psychological flexibility and post-intervention for executive function were calculated. Correlations ranged from 0.68 for emotional control to 0.86 for task monitoring. The results suggested correlations for inhibition $(r=0.80)$ and initiation $(r=0.78)$. While most of other subscale correlations were $\sim 0.70$, the index variables for BRI, MI, and GEC showed correlations of $\sim 0.80$.

\section{Discussion}

The aim of the present pilot study was to examine the effects of a 3-week, tailor-made, client-centered ACT intervention on mental health, psychological flexibility, and executive function of participants institutionalized for severe SUD. 
Table 3 Summary of individual change between pre-intervention and post-intervention for all clinical scales

\begin{tabular}{|c|c|c|c|c|c|c|c|}
\hline Column I & Column 2 & Column 3 & Column 4 & Column 5 & Column 6 & Column 7 & Column 8 \\
\hline \multirow[t]{2}{*}{ Behavior concept } & \multirow[t]{2}{*}{ Instrument } & \multirow{2}{*}{$\begin{array}{l}\text { Clinical scales/single } \\
\text { items - questions in } \\
\text { BRIEF-A }\end{array}$} & \multicolumn{5}{|c|}{$\begin{array}{l}\text { Frequency distribution for change between pre-observation } \\
\text { and post-observation }\end{array}$} \\
\hline & & & $\begin{array}{l}\text { Strong } \\
\text { negative } \\
\text { trend }\end{array}$ & $\begin{array}{l}\text { Negative } \\
\text { tendency }\end{array}$ & $\begin{array}{l}\text { Status } \\
\text { quo }\end{array}$ & $\begin{array}{l}\text { Positive } \\
\text { tendency }\end{array}$ & $\begin{array}{l}\text { Strong } \\
\text { positive } \\
\text { trend }\end{array}$ \\
\hline \multirow[t]{3}{*}{ Mental health status } & DASS-2I & Depression & 3 & I & 9 & 2 & 3 \\
\hline & & Anxiety & 2 & 2 & 10 & 3 & I \\
\hline & & Stress & 1 & 5 & 7 & 3 & 2 \\
\hline Psychological flexibility & AAQ-II & 0. Psychological flexibility & 1 & 1 & 4 & 9 & 3 \\
\hline Executive function - & BRIEF-A BRI & I. Inhibition & 0 & 0 & 10 & 8 & 0 \\
\hline \multirow[t]{3}{*}{ behavioral regulation } & & 2. Shift & 0 & 2 & 11 & 1 & 4 \\
\hline & & 3. Emotional control & 1 & 1 & 10 & 5 & I \\
\hline & & 4. Self-monitoring & 0 & 3 & 10 & 3 & 2 \\
\hline Executive function - & BRIEF-A MI & 5. Initiate & 0 & 1 & 12 & 5 & 0 \\
\hline \multirow[t]{4}{*}{ metacognition } & & 6. Working memory & 0 & 3 & 12 & 2 & I \\
\hline & & 7. Plan/organize & 0 & 1 & 15 & 1 & I \\
\hline & & 8. Task monitoring & 0 & 3 & 8 & 7 & 0 \\
\hline & & 9. Organization of materials & 2 & 2 & 11 & 3 & 0 \\
\hline \multirow[t]{2}{*}{ Outcome variables only } & & $\begin{array}{l}\text { Sum for scales } 0-9 \text { for no. of } \\
\text { change observations }(n=18)\end{array}$ & 4 & 17 & 103 & 44 & 12 \\
\hline & & $\begin{array}{l}\text { Sum in } \% \text { for no. of } \\
\text { observations }=180\end{array}$ & 2.2 & 9.4 & 57.2 & 24.4 & 6.7 \\
\hline \multirow[t]{2}{*}{ All clinical scales } & & $\begin{array}{l}\text { Sum for no. of change } \\
\text { observations for } n=18\end{array}$ & 10 & 25 & 129 & 52 & 18 \\
\hline & & $\begin{array}{l}\text { Sum in } \% \text { for no. of } \\
\text { observations }=234\end{array}$ & 4.3 & 10.7 & 55.1 & 22.2 & 7.7 \\
\hline
\end{tabular}

Notes: Interpretation key for individual change classified into five categories mirroring the shift in assessment categories from pre-observation to post-observation. Strong negative trend, decreasing two assessment categories; negative tendency, decreasing one assessment category; status quo, the same assessment category; positive tendency, increasing one assessment category; strong positive trend, increasing two assessment categories.

Abbreviations: DASS-2I, Depression, Anxiety and Stress Scale - 2I; AAQ-II, Acceptance and Action Questionnaire - II; BRIEF-A, Behavior Rating Inventory of Executive Function - Adult Version; BRI, Behavioral Regulation Index; MI, Metacognition Index.

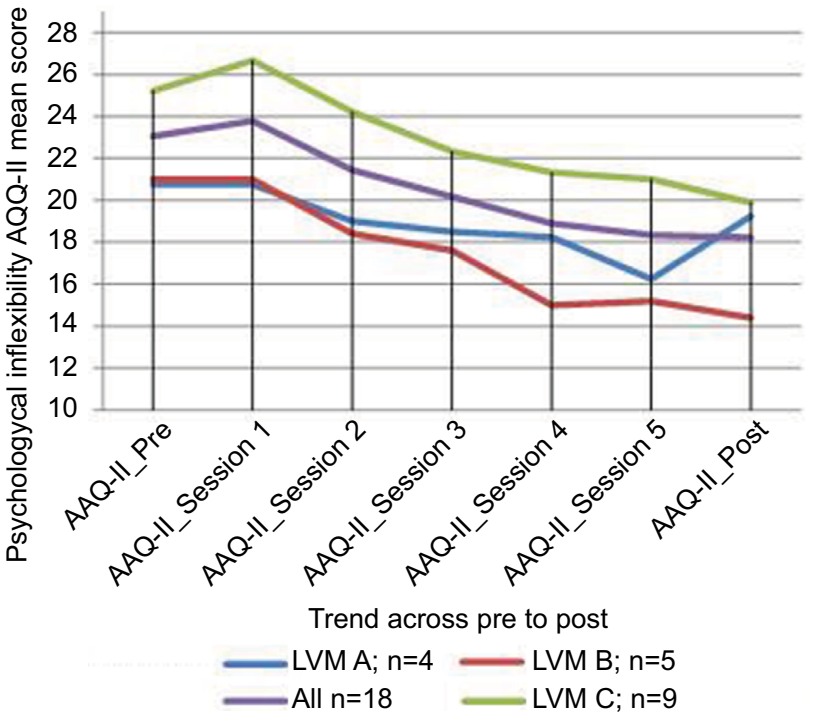

Figure I Psychological inflexibility mean trends by LVM home for all participants $(n=18)$.

Note: Low score indicates high psychological flexibility.

Abbreviation: AAQ-II, Acceptance and Action Questionnaire - II.

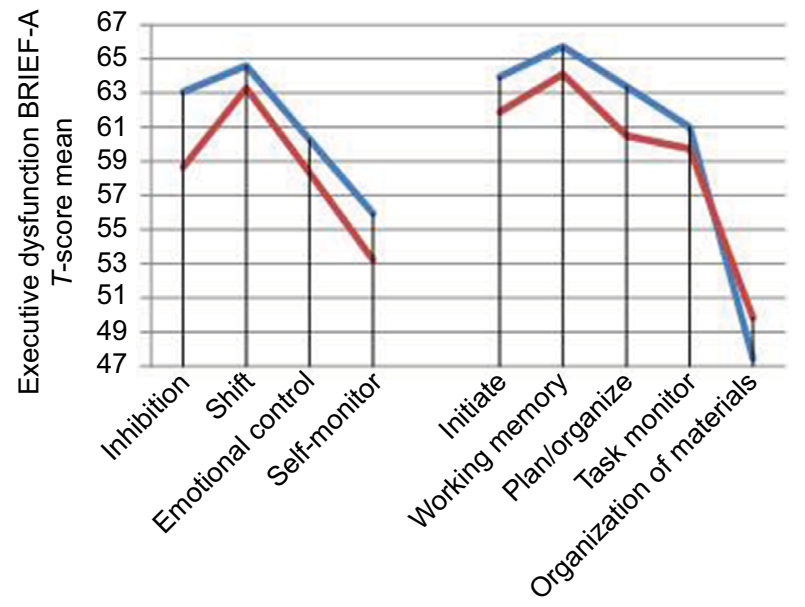

Left: Behavioral regulation subscales Right: Metacognition subscales

$$
\text { Pre all } n=18 \quad \text { Post all } n=18
$$

Figure 2 Executive dysfunction mean $T$-score trends using the BRIEF-A subscales at pre- and post-intervention time points $(n=18)$.

Note: High $T$-score represents high executive dysfunction.

Abbreviation: BRIEF-A, Behavior Rating Inventory of Executive Function - Adult Version. 
The majority of the participants reported no change in mental health, which is in line with other studies implying that rehabilitation takes time and that there may be an "incubation effect" ${ }^{37,38}$ There may be different reasons for this effect, one of which may be reactivity to DASS 21 , rendering the participants more conscious of their sometimes tragic situation.

Concerning the number of change observations among the 18 participants outlined in Table 3 for psychological flexibility and executive function, $31 \%$ (columns 7 and 8 ) implied an improvement across the 10 scales (AAQ and BRIEF-A), whereas $57 \%$ (column 6 ) remained status quo and $12 \%$ (columns 4 and 5) reported a negative change after a 3-week ACT intervention. More specifically, the changes in outcomes preintervention and post-intervention suggested that psychological flexibility had the most positive outcome, and also, executive functions implied a change in a positive direction across time, with the changes shown in inhibition, task monitoring, and emotional control. Since inhibition has been shown to have an association with SUD $^{39}$ and is an important process during rehabilitation, the result in the present pilot study suggesting a positive change in inhibition is hence promising. Substantial correlations were observed between psychological flexibility and executive functions, implying promise for more advanced causal modeling of data in future larger scale studies.

\section{Limitations and implications}

There are limitations that need to be mentioned. This pilot study was carried out without a matched control group, thus increasing the plausibility that factors, other than $\mathrm{ACT}$, were influencing the results. To give an opinion on statistical significant results, the study would have required a much larger sample and resources; however, since these individuals constitute a multiproblematic target group (e.g., double diagnoses, homelessness, trauma, brain damage) being difficult to reach and to involve in research projects, a convenience sample was used. Hence, due to difficulties in involving the individuals in the study for a long period of time after the intervention, no measurements at later points in time were made, a consequence that makes the effects of ACT on the results only suggestive. The analyses were therefore descriptive, and there was no possibility of testing the observed effects of the intervention for statistical significance. Valid information about trends and improvement, however, was mapped in the follow-up data for participants and summarized in order to discern any changes. Although these data may be considered as anecdotal in nature, thus making inference difficult, understanding patterns of change after a short ACT intervention as a function of etiology and cognitive ability makes the importance of individual follow- up all the more important. Individual follow-up provides information for optimizing individualized rehabilitation, a crucial strategy in this heterogeneous group.

Furthermore, there are also some threats to external validity that, for example, pertain to sample characteristics (to what extent the present findings can be generalized to other clients with SUD who vary in, e.g., social background, education, and age). Contextual characteristic (a novelty of ACT) and reactivity (special arrangements for the study) may also have had an influence on the present findings.

Results from earlier studies suggest, however, that ACT is a promising outpatient treatment model for SUD, ${ }^{30}$ and the preliminary findings from the current study suggest that ACT may be a treatment worthy further investigation within an institutional context. To conclude, in order to gain research evidence from institutional settings, further development and implementation of ACT on a larger scale study, including the maintenance phase in the individual and follow-up long after the intervention, is needed.

\section{Conclusion}

The pilot study indicates that ACT can improve psychological flexibility and executive function. Clinical gains were achieved both at LVM home and at the individual level.

Since the sample size does not provide adequate statistical power to generalize and to draw firm conclusions concerning intervention effects, findings are descriptive and preliminary in nature. Further development and implementation of ACT on a larger scale study, including the maintenance phase and a follow-up, is needed.

\section{Acknowledgments}

This pilot study was conducted with support from the SiS. We want to thank SiS colleagues: Karin Pettersson, Ann Rundberg, Annie Josefsson, Madeleine Ritzman, and Tom Persson. We also want to thank Dr. Ola Schenström for his support with mindfulness practices, Professor Kelly Wilson for sharing pearls of wisdom, and Margot Trotter Davis, $\mathrm{PhD}$, for assisting with her valuable expertise. Last, but not the least, we want to thank our wonderful participants who were our greatest inspiration and motivation.

\section{Disclosure}

The authors report no conflicts of interest in this work.

\section{References}

1. Grant BF, Stinson FS, Dawson DA, et al. Prevalence and co-occurrence of substance use disorders and independent mood and anxiety disorders. Results from the National Epidemiologic Survey on alcohol and related conditions. Arch Gen Psychiatry. 2004;61(8):807-816. 
2. Hayes SC, Levin M. Mindfulness and Acceptance for Addictive Behaviors. Applying Contextual CBT to Substance Abuse and Behavioral Addictions. Oakland, CA: Context Press; 2012.

3. American Psychiatric Association. Diagnostic and Statistical Manual of Mental Disorders. 5th ed. Washington, DC: APA; 2013.

4. Eriksson A, Palm J, Storbjörk J. Kvinnor och män i svensk missbruksbehandling: En beskrivning av klientgruppen inom socialtjänstens missbrukarvård i Stockholms län 2001-2002. [Women and men in substance abuse care: A description of the client group in social services drug addiction in Stockholm 2001-2002]. 2003. Swedish.

5. Roehrs T, Roth T. Sleep, sleepiness, and alcohol use. Alcohol Res Health. 2001;25(2):101-109.

6. Adinoff B, Junghanns K, Kiefer F, Krishnan-Sarin S. Suppression of the HPA axis stress-response: implications for relapse. Alcohol Clin Exp Res. 2005;29(7):1351-1355.

7. Hasin DS, Stinson FS, Ogburn E, Grant BF. Prevalence, correlates, disability, and comorbidity of DSM-IV alcohol abuse and dependence in the United States. Arch Genet Psychiatry. 2007;64(7):830-842.

8. Wilens TE, Morrison NR. Substance-use disorders in adolescents and adults with ADHD: focus on treatment. Neuropsychiatry. 2012;2(4): 301-312.

9. Fein G, Di Sclafani V, Cardenas VA, Goldmann H, Tolou-Shams M, Meyerhoff DJ. Cortical gray matter loss in treatment-naive alcohol dependent individuals. Alcohol Clin Exp Res. 2002;26:558-564.

10. Roth RM, Isquith PK, Gioia GA. BRIEF-A Behavior Rating Inventory of Executive Function - Adult Version. Odessa, FL: PAR; 2005.

11. Lawrence AJ, Luty J, Bogdan NA, Sahakian BJ, Clark L. Impulsivity and response inhibition in alcohol dependence and problem gambling. Psychopharmacology. 2009;207(1):163-172.

12. Livheim F, Hayes L, Ghaderi A, et al. The effectiveness of acceptance and commitment therapy for adolescent mental health: Swedish and Australian Pilot Outcomes. J Child Family Stud. 2014;24: 1016-1030.

13. Hayes SC, Luoma JB, Bond FW, Masuda A, Lillis J. Acceptance and commitment therapy: model, processes and outcomes. Behav Res Ther. 2006;44(1):1-25.

14. Hayes SC, Strosahl KD, Wilson KG. Acceptance and Commitment Therapy. The Process and Practice of Mindful Change. 2nd ed. New York, NY: Guilford; 2012.

15. Heffner M, Eifert GH, Parker BT, Hernandez DH, Sperry JA. Valued directions: acceptance and commitment therapy in the treatment of alcohol dependence. Cognit Behav Prac. 2003;10:378-383.

16. Peterson CL, Zettle RD. Treating inpatients with comorbid depression and alcohol use disorders: a comparison of acceptance and commitment therapy and treatment as usual. Psychol Rec. 2009;59:521-536.

17. Batten BV, Hayes SC. Acceptance and commitment therapy in the treatment of comorbid substance abuse and post-traumatic stress disorder: a case study. Clin Case Stud. 2005;4(3):246-262.

18. Smout MF, Longo M, Harrison S, Minniti R, Wickes W, White JM. Psychosocial treatment for methamphetamine use disorders: a preliminary randomized controlled trial of cognitive behavior therapy and acceptance and commitment therapy. Subst Abus. 2010;31(2):98-107.

19. Twohig MP, Shoenberger D, Hayes SC. A preliminary investigation of acceptance and commitment therapy as a treatment for marijuana dependence in adults. J Appl Behav Anal. 2007;40(4):619-632.
20. Luoma JB, Hayes SC, Kohlenberg G. Substance abuse and psychological flexibility: the development of a new measure. Addict Res Theory. 2011;19(1):3-13.

21. Blackledge JT. Disrupting verbal processes: cognitive defusion in acceptance and commitment therapy and other mindfulness-based psychotherapies. Psychol Rec. 2007;57(4):555-577.

22. Blackledge JT, Ciarrochi JV, Deane FP, editors. Acceptance and Commitment Therapy. Contemporary Theory, Research and Practice. Bowen Hills, QLD, Australia: Australian Academic Press; 2009.

23. Luoma JB, Hayes SC, Walser RD. Learning ACT: An Acceptance \& Commitment Therapy Skills-Training Manual for Therapists. Oakland, CA: New Harbinger; Reno, NV: Context Press; 2007.

24. Gioia GA, Isquith PK, Guy S, Kenworthy L. Behavior rating inventory of executive function. Child Neuropsychol. 2000;6(3):235-238.

25. Stuss D, Alexander M. Affectively burnt in: a proposed role of the right frontal lobe. Memory, consciousness, and the Brain: The Tallin Conference. Philadelphia: Psychology Press; 2000.

26. Goleman D. Focus: the Hidden Driver of Excellence. New York, NY: HarperCollins; 2013.

27. Goleman D [webpage on the Internet]. Exercising the Mind to Treat Attention Deficits; 2014. Available from: http://nyti.ms/1gwioGQ Accessed June 20, 2017.

28. Lezak MD, Howieson DB, Loring DW, Hannay HJ, Fischer JS. Neuropsychological Assessment. New York, NY: Oxford University Press; 2004.

29. Bradshaw JL. Developmental Disorders of the Frontostriatal System. Hove and New York: Psychology Press/Taylor \& Francis Group; 2001.

30. Tang Y-Y, Hölzel BK, Posner MI. The neuroscience of mindfulness meditation. Neuroscience. 2015;16(4):213-225.

31. Jha AP, Krompinger J, Baime MJ. Mindfulness training modifies subsystems of attention. Behav Neurosci. 2007;7(2):109-119.

32. Wilson KG. The Wisdom to Know the Difference - An Acceptance \& Commitment Therapy Workbook for Overcoming Substance Abuse. Oakland, CA: New Harbinger Publications; 2012.

33. Wilson KG, Byrd MR. Acceptance and commitment therapy for substance abuse and dependence. In: Hayes SC, Strosahl K, editors. $A$ Practical Guide to Acceptance and Commitment Therapy. New York, NY: Springer Press; 2004:153-184.

34. Sundquist J, Lilja $\AA$, Palmér K, et al. Mindfulness group therapy in primary care patients with depression, anxiety and stress and adjustment disorders: randomised controlled trial. Br J Psychiatry. 2015;206(2):128-135.

35. Brown TA, Chorpita BF, Korotitsch W, Barlow DH. Psychometric properties of the Depression Anxiety Stress Scales (DASS) in clinical samples. Behav Res Therapy. 1997;35(1):79-89.

36. Bond FW, Hayes SC, Baer RA, et al. Preliminary psychometric properties of the Acceptance and Action Questionnaire-II: a revised measure of psychological flexibility and acceptance. Behav Ther. 2011;42:676-688.

37. Clarke S, Kingston J, James K, Bolderston H, Remington B. Acceptance and commitment therapy group for treatment-resistant participants: a randomized controlled trial. J Contextual Behav Sci. 2014;3(3):179-188.

38. Livheim F. ACT - Att hantera stress och främja hälsa. [To prevent stress and promote health]. Sweden: Precens, Centrum för folkhälsa \& Livheim; 2008. Swedish.

39. Lawrence AJ, Luty J, Bogdan NA, Sahakian BJ, Clark L. Problem gamblers share deficits in impulsive decision-making with alcoholdependent individuals. Addiction. 2009;104(6):1006-1015.
Substance Abuse and Rehabilitation

\section{Publish your work in this journal}

Substance Abuse and Rehabilitation is an international, peer-reviewed, open access journal publishing original research, case reports, editorials, reviews and commentaries on all areas of addiction and substance abuse and options for treatment and rehabilitation. The manuscript management system is completely online and includes a very quick and fair peer-review system. Visit http://www.dovepress.com/testimonials.php to read real quotes from published authors. 